\title{
Methanolic extract of Malus domestica mitigates formalin - Induced derangements in small intestinal motility and transit
}

\author{
V.O. Oka', V.U. Nna', E.G. Inyang'1, J.B. Ikpe'1 \\ ${ }^{1}$ Department of Physiology, Faculty of Basic Medical Sciences, College of Medical Sciences, University of Calabar, Calabar, Cross River State, \\ Nigeria
}

\section{A B STR A C T}

\begin{abstract}
Objective: This study was carried out to ascertain the effect of formalin ingestion on small intestinal motility and transit, and the impact of treatment with Malus domestica on same. Methodology: Twenty albino wistar rats weighing 180 - $200 \mathrm{~g}$ were used for this study. The animals were randomly divided into 4 groups of 5 rats each. Group 1 served as control, group 2 - formalin treated group, group 3 - M. domestica treated group and group 4 - formalin treated group administered with $M$. domestica. The daily oral dose employed in this study was $2.5 \mathrm{mg} / 100 \mathrm{~g}$ and $40 \mathrm{mg} / 100 \mathrm{~g}$ for formalin and $M$. domestica respectively. After 21 days of treatment, intestinal transit experiment was carried out on the animals and intestinal motility was also carried out on the isolated rat ileum using graded doses of acetylcholine and atropine. Results: Basal contraction of isolated rat ileum was significantly $(p<0.001)$ lower in the formalin treated and $M$. domestica treated group compared to control. It was significantly $(p<0.001)$ higher in Formalin $+M$. domestica group compared to formalin treated and $M$. domestica treated group. Formalin $+M$. domestica group showed a dose dependent increase in contraction of isolated rat ileum when acetylcholine was administered, and a significantly $(p<0.001)$ lower percentage relaxation in response to atropine administration, compared to formalin treated and $M$. domestica treated group. Small intestinal transit was significantly $(\mathrm{p}<0.05)$ reduced in formalin treated and $M$. domestica treated group, compared to control. It was also significantly $(p<0.05)$ reduced in formalin $+M$. domestica group compared to formalin treated and $M$. domestica treated group. Conclusion: Malus domestica reverses formalin induced decrease in small intestinal motility and transit and may be beneficial in treating constipation occasioned by ingestion of formalin.
\end{abstract}

Access this article online

Website:

http://nepjol.info/index.php/AJMS

Key words: Formalin, intestinal motility, intestinal transit, Malus domestica

\section{INTRODUCTION}

Malus domestica (apple) belongs to family Rosaceae (rose family), and cultivated in Asia, Europe and North America. Today, apple has become a widely cultivated fruit. Apart from its common use as food, apple has been proven to have strong antioxidant property. ${ }^{1}$ Apple has been reported to be beneficial in weight management, ${ }^{2,3}$ prevention of cardiovascular disease, ${ }^{4-6}$ reducing the risk of developing lung cancer, ${ }^{7}$ reducing the frequency of asthmatic attacks and reduce bronchial hypersensitivit. ${ }^{8-10}$ Additionally, apple intake has been linked to reduced risk of developing type 2 diabetes mellitus; ${ }^{11}$ little wonder the old proverb, "an apple a day keeps the doctor away".

Formalin is a solution of formaldehyde gas (obtained by oxidation of methanol) in water. A saturated solution of formaldehyde contains about $40 \%$ by volume, or $37 \%$ by weight, of the gas. ${ }^{12}$ Formaldehyde in aqueous solution is unstable and tends to polymerize, forming larger molecules that are insoluble and therefore precipitate out of the solution. For this reason, methanol, which prevents polymerization, is added to the solution. Formaldehyde also occurs naturally in the environment. It is produced in 
small amounts by most living organisms as part of normal metabolic processes. ${ }^{12}$

Formalin is used as an embalming fluid and for the preservation of animal specimens and tissue samples. ${ }^{13-15}$ It is also used, generally in a much more dilute form, as a disinfectant, and anti-bacterial and in aquariums for treating parasite infections in fish. ${ }^{14,15}$ The disinfectant properties of the solution are due to the presence of formaldehyde, which also gives it a pungent, irritating smell.

The United States Environmental Protection Agency (EPA) classified formaldehyde as a probable human carcinogen, when exposed to conditions of unusually high contact. ${ }^{16-18}$ Since then, some studies on humans have suggested that formaldehyde exposure is associated with certain types of cancer. ${ }^{19-21}$ When exposed to formaldehyde, some individuals may experience various short-term effects. Formaldehyde has been classified as a known human carcinogen (cancer-causing substance) by the International Agency for Research on Cancer and as a probable human carcinogen by the United States Environmental Protection Agency. Research studies of workers exposed to formaldehyde have suggested an association between formaldehyde exposure and several cancers, including nasopharyngeal cancer and leukemia. ${ }^{12-14}$

Intestinal motility and transit are important indicators of the functionality of the small bowel. Delayed or accelerated transit have been implicated in the pathogenesis of constipation and diarrhoea, respectively. ${ }^{22}$ A number of gastrointestinal hormones affect small intestinal transit by influencing gastric emptying and intestinal motility. ${ }^{23}$ Cholecystokinin (CCK) for example, secreted by I - cells of the small intestine in response to the presence of acid rich chyme inhibits gastric motility and increases intestinal motility. ${ }^{23}$ To this end, ingested food materials rich in fatty acids, peptides and amino acids will increase small intestinal transit.

In Northern Nigeria, formalin is consumed by a greater population of the youths in a mixture with energy drinks; a combination nick named "Madaran Sukudai". ${ }^{24}$ The youths have linked the combination to increased alertness. In view of the above health hazards associated with formalin contact or ingestion, it became important to ascertain its effect on small intestinal motility and transit, and to ascertain the impact of treatment with extract of Malus domestica on same.

\section{MATERIAL AND METHODS}

Plant Material and Preparation of Methanolic Extract Fresh green Malus domestica (apples) weighing 70 - $100 \mathrm{~g}$ were purchased from apple vendors in Calabar, Nigeria. The apples were rinsed with clean water to remove debris and sand, after which they were cut into slender slices and dried in AstellHearson oven at $45^{\circ} \mathrm{C}$. The dried sample was ground to powder using an electric grinding machine to obtain a weight of $320 \mathrm{~g}$. The ground apple was homogenized with $1535 \mathrm{ml}$ of methanol, after which it was filtered using Whatman's filter paper and the exudate was then refrigerated for 48 hrs for further homogenization. At the end of $48 \mathrm{hrs}$, the extract was heated using an electric hot plate to allow for evaporation of the methanol. After complete evaporation of the methanol, the pasty extract was then introduced into a sterile sample bottle and preserved in the refrigerator. The stock solution was prepared by dissolving $15 \mathrm{~g}$ of the extract in $10 \mathrm{ml}$ of distil water to obtain a concentration of $1500 \mathrm{mg} / \mathrm{ml}$, and stored in the refrigerator at $4^{\circ} \mathrm{C}$ until required for use. The median lethal dose of the extract was carried out by method of Lorke, (1983) $)^{25}$ and found to be non toxic at the highest tested dose of $1600 \mathrm{mg} / \mathrm{kg}$. The dosage of $40 \mathrm{mg} / 100 \mathrm{~g}$ was adopted for this study.

\section{Animal Preparation and Protocol}

Twenty albino Wistar rats weighing 180 - $200 \mathrm{~g}$ were used for this study. Animals had access to food and water ad libitum, and were placed in well ventilated cages, exposed to normal temperature and 12/12 hours light/dark cycle. After fourteen days of acclimatization, the animals were randomly divided into four groups of five animals each. The groups were labeled and treated as follows: Group 1 - control group, group 2 - formalin treated group, group 3 - control animals administered Malus domestica, group 4 - formalin treated group administered Malus domestica.

\section{Formalin treatment}

Formalin treatment began after acclimatization. Formalin was orally administered to group 2 and 4 at a dose of $2.5 \mathrm{mg} / 100 \mathrm{~g}$. Administration was facilitated by the use of a syringe and orogastric tube. The syringe and oragastric tube used for formalin administration was different from that used to administer methanolic extract of $M$. domestica to avoid contamination.

\section{Extract administration}

After acclimatization, administration of methanolic extract of Malus domestica commenced in group 3 and 4. Group 4 was administered methanolic extract of Malus domestica along side formalin. The dosage of methanolic extract of Malus domestica used in this study was $40 \mathrm{mg} / 100 \mathrm{~g}$. All experiments were performed in accordance with the ethical standards laid down in the 1964 declaration of Helsinki.

\section{Determination of Small Intestinal Transit}

Intestinal transit was measured using the method of Uwagboe and Orimilique, ${ }^{26}$ and modified by Nna et al. ${ }^{27}$ The rats in the different experimental groups were starved 
for 24 hours but were allowed access to water. Starving the animals was employed to clear the bowel of all food materials. $10 \mathrm{~g}$ of activated charcoal was thoroughly mixed with $1 \mathrm{~g}$ gum Arabic in $100 \mathrm{ml}$ of distil water to serve as the marker substance. Each animal was gavaged with $2 \mathrm{ml}$ of the marker substance, orally using a metallic ( $8 \mathrm{~cm}$ long) intubating syringe. The animals were timed for $60 \mathrm{~min}$ each. At the expiration of each $60 \mathrm{~min}$, the rats were introduced into a confined chamber with $30 \%$ of the chamber's volume containing $\mathrm{CO}_{2}$ from a compressed gas cylinder $\left(\mathrm{CO}_{2}\right.$ - euthanesia). ${ }^{27}$ As soon as righting reflex was lost for more than 30 seconds, the animal was removed from the chamber and cervical decapitation employed to ensure death. The abdomen was immediately cut open through the linea alba to minimize bleeding. The duodenum was then identified as the continuation of the pyloric sphincter while the ileocecal sphincter was also prominent at the cecal end. The duodenum was cut away from the pyloric sphincter and the ileum was also cut at the ileocecal sphincter. The small intestine was immediately straightened and the location of the marker was clearly visible along the small intestine. A thread was used to tie the intestine at the point where the marker stopped. The total length of the intestine and the length travelled by the marker were measured and recorded with the help of a measuring tape.

The intestinal transit was calculated as:

$\frac{\text { Length travelled by black marker substance }}{\text { Total length of small intestine }} \times 100$

The values were recorded and differences analyzed statistically.

\section{Determination of Small Intestinal Motility}

The rats were starved 24 hours prior to experiment. The animals were sacrificed by stunning and incision quickly made through the linea alba to expose the intestine. The proximal ileum was located and isolated, then placed in a container of tyrode solution and aerated. The ileum was then cut into $3 \mathrm{~cm}$ long segments, and mounted at one end to a fixed support in an organ bath. The other end of the ileum was fixed to a horizontal balance writing lever tangential to a kymograph drum. The tissue was allowed to equilibrate for 60 minutes during this period the bathing solution was replaced with tyrode solution at 15 minutes interval to avoid accumulation of metabolites. The tissue was later challenged with graded doses of acetylcholine $\left(10^{-4}\right.$ to $\left.10^{-10} \mathrm{mg}\right)$ and later with atropine $(0.1 \mathrm{mg})$, at an interval of 1 minute per administration.

\section{Statistical Analysis}

All results are presented as mean \pm standard error of mean (SEM). Data were analyzed using one way ANOVA, followed by the least significant difference (LSD) procedure for significant $F$ values, $P=.05$ was considered significant. Computer software SPSS and Excel Analyzer was used for the analysis.

\section{RESULTS}

Basal Height of Contraction in the Different Experimental Groups

The mean basal height of contraction was $4.8 \pm 0.3,2.1$ $\pm 0.1,2.6 \pm 0.1$ and $4.8 \pm 0.3 \mathrm{~mm}$ for control, formalin, $M$. domestica and formalin $+M$. domestica group respectively. Basal height of contraction was significantly $(\mathrm{p}<0.001)$ lower in the formalin treated and M. domestica treated group, compared to control. Basal height of contraction was significantly $(\mathrm{p}<0.001)$ higher in formalin $+M$. domestica group, compared to formalin treated and $M$. domestica treated group (Figure 1).

Effect of Graded Doses of Acetylcholine (Ach) on Intestinal Motility in the Different Experimental Groups The response to graded doses of acetylcholine with concentration of $10^{-9}$ to $10^{-4} \mathrm{~g} / \mathrm{ml}$ by the isolated rat ileum of the control, formalin, $M$. domestica and formalin $+M$. domestica group is shown in figure 2. At low doses, there was a gradual relaxation of the ileum in the formalin treated group, followed by a gradual increase in contractile response of the ileum at a concentration of $10^{-7}$. At low concentrations, there was reduction in isolated rat ileum contraction in $M$. domestica treated group. The contractions gradually increased at a concentration of $10^{-8}$.

The isolated rat ileum in the formalin $+M$. domestica group showed an increase in contraction from the onset of Ach

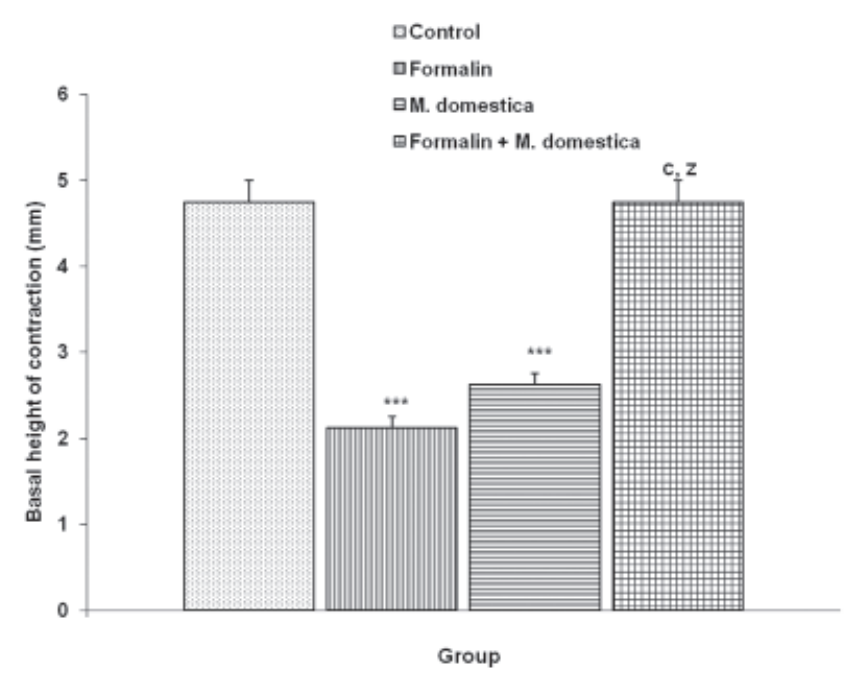

Figure 1: Comparison of basal heights of contraction in the different experimental groups. Values are mean $\pm S E M, n=5$. ${ }^{* * *} \mathrm{p}<0.001$ vs control; $\mathrm{c}=\mathrm{p}<0.001$ vs formalin; $\mathrm{z}=\mathrm{p}<0.001$ vs $M$. domestica 
administration. The extent of increase in contraction in this group was directly proportional to the dose of Ach administered (Figure 2).

\section{Effect of Atropine on Intestinal Motility in the Different Experimental Groups}

The percentage decrease in contraction of the isolated rat ileum following atropine administration was $52.5 \pm$ 4.8, $207.5 \pm 14.9,195 \pm 9.6$ and $8.8 \pm 11.3 \%$ for control, formalin, $M$. domestica and formalin $+M$. domestica group respectively. Percentage decrease in contraction was significantly $(\mathrm{p}<0.001)$ higher in formalin and $M$. domestica treated groups, compared to control and formalin $+M$. domestica groups. Percentage decrease in contraction was significantly $(\mathrm{p}<0.001)$ lower in formalin $+M$. domestica group compared to formalin treated and $M$. domestica treated group (Figure 3).

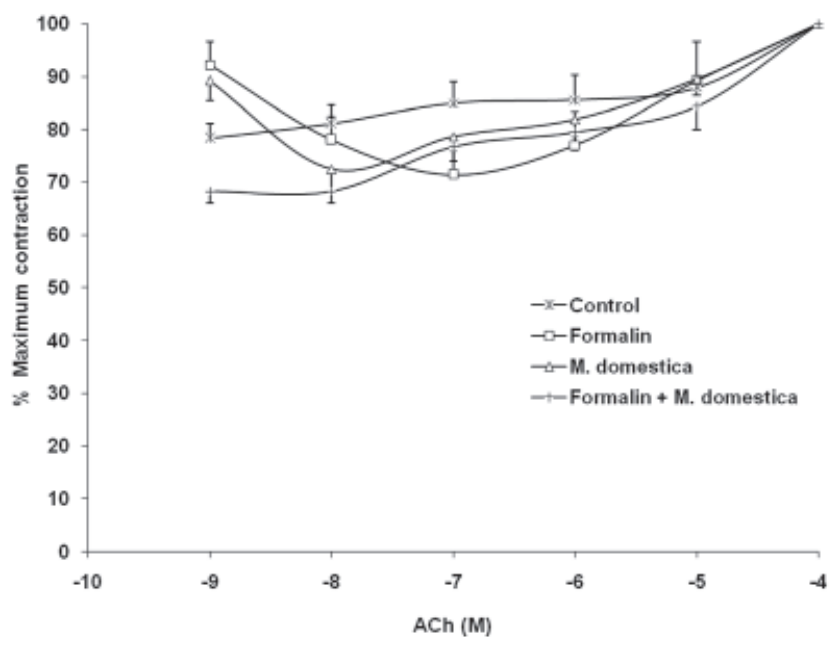

Figure 2: Contraction of rat ileum in response to graded concentrations of acetylcholine in the different experimental groups. Values are mean \pm SEM, $n=5$

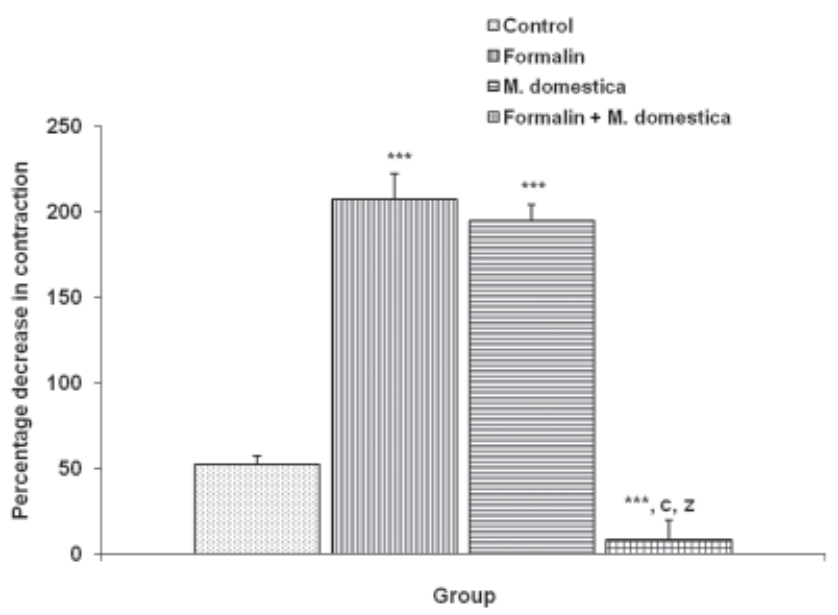

Figure 3: Decrease in contraction of rat ileum in response to atropine in the different experimental groups. Values are mean \pm SEM, $n=5$. ${ }^{* * *} p<0.001$ vs control; $c=p<0.001$ vs formalin; $z=p<0.001$ vs $M$. domestica
Intestinal Transit in the Different Experimental Groups The mean value of percentage transit for control, formalin, $M$. domestica and formalin $+M$. domestica group was $41.1+$ $1.5,28.1+3.7,30.9+4.0$ and $38.7+1.7 \%$ respectively. Percentage transit was significantly $(\mathrm{p}<0.05)$ lower in the formalin and $M$. domestica treated groups, compared to control. Formalin $+M$. domestica group had a significantly $(p<0.05)$ higher percentage transit, compared to formalin treated group (Figure 4).

\section{DISCUSSION}

The prevalence of gastrointestinal (GI) motility and transit disorders is high in the general population, and the symptoms of disturbed GI motility are often a significant problem in patients with other medical problems. ${ }^{28,29}$

In Northern Nigeria, formalin is consumed in combination with energy drinks, a combination named Madaran Sukudai, also called "soak and die". Physico-chemical analysis has been carried out on Madaran Sukudai (a local drink in Northern Nigeria), diluted Madaran Sukudai and pure formalin. Both the infrared and UV visible spectroscopic studies on the three solutions revealed that Madaran Sukudai is essentially a dilute formalin solution. ${ }^{24}$ Ingestion of formalin leads to irritation and burns of the mouth and throat, ulceration in the fore stomach and hyperplasia in the glandular stomach of rats. ${ }^{30}$

Oral administration of formalin to the formalin treated group (group 2) significantly reduced the basal height of contraction of rat ileum (Figure 1). Administration of methanolic extract of $M$. domestica to the $M$. domestica group (group 3) also significantly reduced basal height

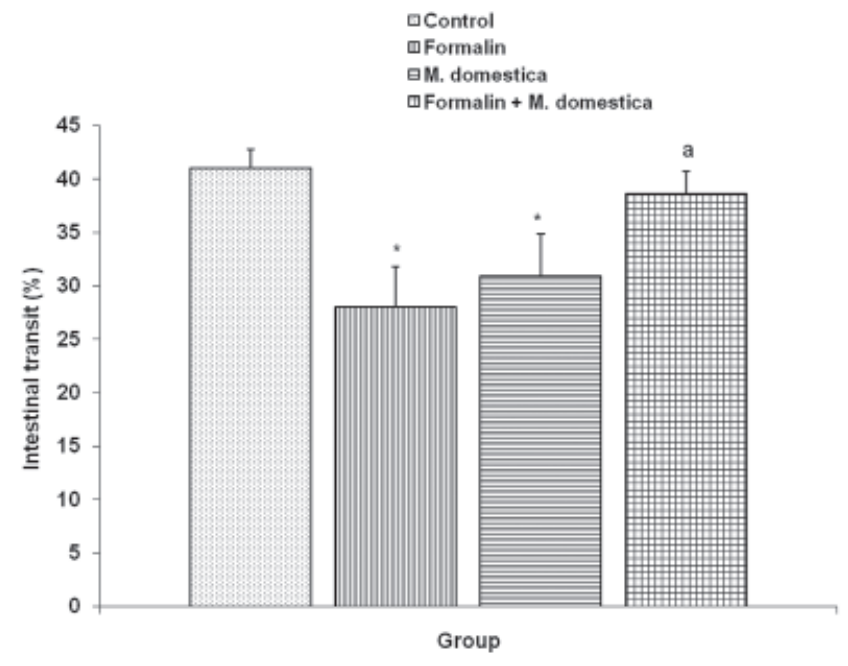

Figure 4: Comparison of percentage intestinal transit in the different experimental groups. Values are mean \pm SEM, $\mathrm{n}=5$. ${ }^{*} p<0.05$ vs control; $a=p<0.05$ vs formalin 
of contraction of the isolated rat ileum. However, when $M$. domestica was co-administered with formalin (group 4), the basal height of contraction was significantly increased to levels observed in the control group.

Chemical agents like acetylcholine (Ach) and atropine, that are known to influence gastrointestinal contraction were used in this study. Ach significantly raised the tone of contraction of the isolated rat ileum in group 2 and 3 , after recording an initial decrease in contraction with low doses. Formalin $+M$. domestica group showed a continuous increase in contraction of isolated rat ileum, following Ach administration (Figure 2). Addition of atropine - an anti cholinegic drug, resulted in a high percentage decrease in contraction in groups 2 and 3, compared to control, with no significant difference between group 2 and 3 (Figure 3). Percentage decrease in contraction of isolated rat ileum was significantly lower in formalin + Malus domestica group (group 4), compared to control.

Intestinal transit which is dependent on the rate and force of smooth muscular contraction of the gut, ${ }^{27}$ was significantly reduced in formalin treated and $M$. domestica treated group compared to control. Although the percentage transit was lower in the formalin treated group compared to $M$. domestica group, the difference was not significant. Co-administration of formalin and M. domestica (formalin $+M$. domestica group) significantly increased the small intestinal transit compared to formalin treated and M. domestica treated groups (Figure 4).

Phytochemical studies on $M$. domestica (apple) has shown that it contains carbohydrates, flavonoids, phenols, tannins, terpenoids, phlobatannins, cardiac glycosides and vitamins. ${ }^{31}$ Apples have been reported to possess antioxidant activity. ${ }^{1,2}$ The enhancement in percentage transit observed in the formalin $+M$. domestica group may be traced to the antioxidant activity of $M$. domestica, which attempts to reverse the detrimental effects of formalin ingestion on the gastrointestinal tract.

\section{CONCLUSION}

Malus domestica reverses formalin - induced decrease in small intestinal motility and transit and may be beneficial in the treatment of constipation reported in individuals who ingest dilute formalin.

\section{REFERENCES}

1. Wolfe $\mathrm{K}, \mathrm{Wu} \mathrm{X}$ and Liu RH: Antioxidant activity of apple peels. J Agric Food Chem 2003;51:609-614.

2. Eberhardt $\mathrm{M}$, Lee $\mathrm{C}$ and Liu RH. Antioxidant activity of fresh apples. Nature 2000;405:903-904.
3. De Oliviera M, Sichieri R and Moura A. Weight loss associated with a daily intake of three apples or three pears among overweight women. Nutr 2003;19:253-256.

4. Barraj LM, Harnack L, Hong CP, Nettleton JA and Jacobs DR. American Journal of Clinical Nutrition 2007;85(3):895-909.

5. Sesso H, Gaziano JM, Liu S and Buring J. Flavonoid intake and risk of cardiovascular disease in women. Am J Clin Nutr 2003;77:1400-1408.

6. Denis L, Nathalie A, Sandrine B, Richard P, Enora C, Serge H, et al. Dietary fiber intake and risk factors for cardiovascular disease in French adults. Am J of Clin Nutr 2005;82:1185-1194.

7. Feskanich D, Ziegler R, Michaud D, Giovannucci E, Speizer F, WIllett W, et al. Prospective study of fruit and vegetable consumption and risk of lung cancer among men and women. J Natl Cancer Inst 2000;92:1812-1823.

8. Knekt P, Kumpulainen J, Jarvinen R, Rissanen $H$, Heliovaara M, Reunanen A, et al. Flavonoid intake and risk of chronic diseases. Am J Clin Nutr 2002;76:560-568.

9. Shaheen S, Sterne J, Thompson R, Songhurst C, Margetts B and Buerney P. Dietary antioxidants and asthma in adults- population based case-control study. Am J Respir Crit Care Med 2001;164:1823-1828.

10. Butland $B$, Fehily $A$ and Elwood P. Diet, lung function, and lung decline in a cohort of 2512 middle aged men. Thorax 2000; $55: 102-108$

11. Knekt $P$, Kumpulainen J, Jarvinen $R$, Rissanen $H$, Heliovaara $M$, Reunanen $\mathrm{A}$, et al. Flavonoid intake and risk of chronic diseases. Am J Clin Nutr 2002;76:560-568.

12. U.S. Centers for Disease Control Agency for Toxic Substances and Disease Registry (ATSDR). "Toxicological Profile for Formaldehyde." http://www.atsdr.cdc.gov/toxprofiles/tp111.html. 1997.

13. World Health Organization. "IARC Monographs on the Evaluation of Carcinogenic Risks to Humans: Volume 88 Formaldehyde, 2-Butoxyethanol and 1-tert-Butoxy-2-propanol." http://monographs.iarc.fr/ENG/Monographs/vol88/volume88. pdf. 2006.

14. World Health Organization. International Program on Chemical Safety, Environmental Health Criteria 89. Formaldehyde. http:// www.inchem.org/documents/ehc/ehc/ehc89.htm. 1999.

15. U.S. Environmental Protection Agency. Formaldehyde: Hazard Summary. http://www.epa.gov/ttn/atw/hlthef/formalde.html. 2003.

16. U.S. Environmental Protection Agency, Office of Air and Radiation. Report to Congress on Indoor Air Quality, Volume II: Assessment and Control of Indoor Air Pollution, 1989.

17. International Agency for Research on Cancer. IARC Monographs on the Evaluation of Carcinogenic Risks to Humans Volume 88 (2006): Formaldehyde, 2-Butoxyethanol and 1-tertButoxypropan-2-ol. Retrieved June 10, 2011, from: http:// monographs.iarc.fr/ENG/Monographs/vol88/index.php. 2004.

18. National Toxicology Program. Report on Carcinogens, Twelfth Edition. Department of Health and Human Services, Public Health Service, National Toxicology Program. Retrieved June 10, 2011, from: http://ntp.niehs.nih.gov/go/roc12. 2011.

19. Pinkerton LE, Hein MJ and Stayner LT. Mortality among a cohort of garment workers exposed to formaldehyde: An update. Occupational Environmental Medicine 2004;61:193-200.

20. Coggon D, Harris EC, Poole J and Palmer KT. Extended follow-up of a cohort of British chemical workers exposed to formaldehyde. Journal of the National Cancer Institute 2003;95(21):1608-1615.

21. Hauptmann M, Lubin JH, Stewart PA, Hayes RB and Blair A. Mortality from lymphohematopoietic malignancies among workers in formaldehyde industries. Journal of the National Cancer Institute 2003;95(21):1615-1623. 
22. Cann PA, Read NW, Brown C, Hobson N and Holdsworth CD. Irritable bowel syndrome: relationship of disorders in the transit of a single solid meal to symptoms patterns. Gut 1983;24:405411.

23. Osim EE. Elements of Gastrointestinal Tract Physiology. Helimo Associates, Calabar 2002.

24. Owalude SO and Tella AC. "Physico-chemical Analysis and Toxicological Studies of Madaran Sukudai (a local drink in Northern Nigeria)". African Journal of Pure and Applied Chemistry 2008;2(6):61-63. Available online at www.academicjournals.org/ AJPAC/contents/2008cont/June.htm. 2008.

25. Lorke D. A new approach to practical acute toxicity testing. Arch. Toxicol 1983;54:275-287.

26. Uwagboe PE and Orimilikwe SO. Effect of histamine $\mathrm{H} 2$ receptor blocker on gastrointestinal transit in conscious albino rats. Nig J Physiol Scs 1995;11:56-58.

27. Nna VU, Akpan UP, Olubobokun TH, Osim EE and Antai AB. Crude Aloe vera gel increases body weight and reduces small intestinal transit in normal albino wistar rats. Journal of Scientific Research and Reports 2013;2(2):741-753.

28. Drossman DA, Li Z, Andruzzi E, Temple RD, Talley NJ, Thompson WG, et al. U.S. householder survey of functional gastrointestinal disorders. Prevalence, sociodemography, and health impact Dig Dis Sci 1993;38(9):1569-1580.

29. Russo MW, Wei JT, Thiny MT, Gangarosa LM, Brown A, Ringel Y, et al. Digestive and liver diseases statistics. Gastroenterology 2004;126(5):1448-1453.

30. Agency for Toxic Substances and Disease Registry (ATSDR). Toxicological profile for Formaldehyde. Atlanta, GA: U.S. Department of Health and Human Services, Public Health Service. 1999.

31. Vijayalakshmi K, Vanitha V, Sumija R, Ramya P and Umadevi KJ. A comparative study of phytochemicals, antioxidant potential and free radical scavenging activity of Psidium guajava and Malus domestica - An in vitro study. International Journal of Pharmaceutical Research and Development 2011;3(7):38-46.

Authors Contribution:

VOO - Conceived and designed the study, made the first draft of the manuscript; VUN - Concept and design of the study, analysis and interpretation of data, manuscript preparation; EGI - Data collection, literature searches and manuscript preparation; JBI - Data collection, literature searches, manuscript review. All authors reviewed and approved of the final manuscript.

Source of Support: Nil, Conflict of Interest: None declared. 